\title{
Chemotherapy induced nausea and vomiting in bone marrow transplant: the unmet need
}

\author{
Andrea Tendas ${ }^{1} \cdot$ Pasquale Niscola $^{1} \cdot$ Alessio Perrotti ${ }^{1}$. \\ Teresa Dentamaro $^{1}$ - Paolo de Fabritiis ${ }^{1}$ - William Arcese ${ }^{2}$. \\ on behalf of the Rome Transplant Network (RTN) Quality \\ of Life Working Party
}

Received: 12 February 2015 / Accepted: 16 March 2015 / Published online: 28 March 2015

(C) Springer-Verlag Berlin Heidelberg 2015

Dear Editor,

We have read with great interest the paper by Van Laar ES and colleagues entitled "Professional educational needs for chemotherapy-induced nausea and vomiting (CINV): multinational survey results from 2388 health care providers." [1]. We strongly agree that surveys are paramount to detect health care providers needs and plan interventions. However, we would like to highlight a criticism on the results of the survey on the specific concern of CINV management in patients undergoing bone marrow transplant (BMT). This topic is not specifically discussed in the paper. In table 4 , when survey results among hematologists/oncologists are reported topic by topic, the second lowest percentage of "strong agreement" and the highest percentage of "disagreement" in the judgment of physicians, with nurse judgment just barely better, are reported for the issue "Prevent/manage CINV in patients undergoing bone marrow transplant."

It is our opinion that interviewers were not particularly expert in the field of BMT with a low educational need on CINV management in this setting. Indeed, CINV management in BMT is complex [2], knowledge of health care providers is limited, adherence to guidelines is low [3], and moreover, the strength of guidelines recommendations for CINV manage-

Andrea Tendas

tendas.andrea@aslrmc.it

1 Hematology, S. Eugenio Hospital, Piazzale dell’Umanesimo 10, 00144 Rome, Italy

2 Hematology, Stem Cell Transplant Unit, Tor Vergata University, Rome, Italy ment in high-dose chemotherapy is weak, when compared with recommendations for CINV in standard-dose chemotherapy [4]; consequently, contrary to what the reader might deduce, we strongly believe that health care providers need in the field of BMT is high, so that, in order to verify our opinion, we suggest to disseminate the same survey to physicians and nurses operating in this field.

Conflict of interest All authors disclose any financial and personal relationships that could inappropriately influence their work. Authors have full control of all primary data and agree to allow the journal to review their data if requested.

\section{References}

1. Van Laar ES, Desai JM, Jatoi A (2015) Professional educational needs for chemotherapy-induced nausea and vomiting (CINV): multinational survey results from 2,388 health care providers. Support Care Cancer 23(1):151-157

2. Tendas A, Sollazzo F, Bruno A, Cupelli L, Niscola P, Pignatelli AC, Dentamaro T, de Fabritiis P, Arcese W (2012) Obstacles to managing chemotherapy-induced nausea and vomiting in high-dose chemotherapy with stem cell transplant. Support Care Cancer 20(5):891-892. doi:10.1007/ s00520-012-1411-1

3. Tendas A, Sollazzo F, Niscola P, Cupelli L, Carlo C, Mauroni MR et al (2012) Management of chemotherapyinduced nausea and vomiting in adult patients after haematopoietic stem cell transplantation: adherence to guidelines and costs analysis from the Quality of Life Working Party of the Rome Tranplant Network. Bone Marrow Transplant 47:S467-S467

4. Einhorn LH, Grunberg SM, Rapoport B, Rittenberg C, Feyer P (2011) Antiemetic therapy for multiple-day chemotherapy and additional topics consisting of rescue antiemetics and high-dose chemotherapy with stem cell transplant: review and consensus statement. Support Care Cancer 19(Suppl 1):S1-S4. doi:10.1007/s00520-0100920-z 